\title{
3-Chlorotyrosine as a Marker of Protein Damage by Myeloperoxidase in Tracheal Aspirates From Preterm Infants: Association With Adverse Respiratory Outcome
}

\author{
I. HENDRIKJE BUSS, REVATHY SENTHILMOHAN, BRIAN A. DARLOW, NINA MOGRIDGE, \\ ANTHONY J. KETTLE, AND CHRISTINE C. WINTERBOURN \\ Departments of Pathology [I.H.B., R.S., A.J.K., C.C.W.] and Paediatrics [B.A.D., N.M.], Christchurch \\ School of Medicine and Health Sciences, Christchurch, New Zealand
}

\begin{abstract}
ABST
Oxidative injury is implicated in the development of chronic
lung disease in preterm infants with respiratory distress. How-
ever, direct evidence of a causal role is limited and the source of
reactive oxidants has not been identified. We have previously
shown that protein carbonyl levels in tracheal aspirates correlate
positively with myeloperoxidase, suggesting that neutrophil ox-
idants could be the source of this protein injury. We have
extended these observations by measuring 3 -chlorotyrosine, a
specific biomarker of the neutrophil oxidant, hypochlorous acid,
in tracheal aspirate proteins (144 samples) from 69 infants with
birth weight $<1500$ g. 3 -Chlorotyrosine levels were higher in
these infants than in larger infants without respiratory distress
(median 83 compared with 13 mol/mol tyrosine). They corre-
lated strongly with myeloperoxidase activity (correlation coeffi-
cient $0.75, p<0.0001$ ) and to a lesser extent with protein
carbonyls. 3 -Chlorotyrosine levels (at 1 wk after birth) correlated
negatively with birth weight or gestational age. They were
\end{abstract}
significantly higher in infants who developed chronic lung disease (oxygen requirement at $36 \mathrm{wk}$ postmenstrual age) than in those who did not (median 88 and $49 \mu \mathrm{mol} / \mathrm{mol}$ tyrosine, respectively) and correlated with days of supplemental oxygen. 3-Chlorotyrosine was also significantly higher in infants who had lung infection or were Ureaplasma urealyticum positive. Our results are the first evidence that chlorinated proteins are produced in the lungs of premature infants and that they are higher in infection. The higher 3-chlorotyrosine levels in infants who develop chronic lung disease suggest that neutrophil oxidants contribute to the pathology of this disease. (Pediatr Res 53: 455-462, 2003)

\section{Abbreviations}

$\mathbf{F i O}_{2}$, fraction of inspired oxygen

MPO, myeloperoxidase

TA, tracheal aspirate

VLBW, very low birth weight
Free radical generation and oxidative injury are thought to be important mechanisms contributing to morbidity, including chronic lung disease, in very low birth weight (VLBW) infants. These infants have immature lungs in which antioxidant defenses are not fully developed and are frequently exposed to reactive oxidants either from high concentrations of inspired oxygen or activation of neutrophils that accumulate in the lungs as part of an inflammatory response.

Several investigators have measured markers of lipid peroxidation, including breath ethane and pentane, and malondialdehyde in tracheal aspirate (TA) samples from the lungs of

Received April 30, 2002; accepted September 25, 2002.

Correspondence: Professor Christine Winterbourn, Department of Pathology, Christchurch School of Medicine, P.O. Box 4345, Christchurch, New Zealand; e-mail: christine.winterbourn@chmeds.ac.nz

This work was supported by grants from the Health Research Council of New Zealand, New Zealand Lotteries Health Research, and the University of Otago.

DOI: 10.1203/01.PDR.0000050655.25689.CE premature infants (1-4). Protein carbonyls, which can be generated either by direct oxidation of the protein or by covalent linkage of aldehyde products of lipid peroxidation, have also been detected in TA (4-7). Higher levels of the biomarkers have often been detected in the more premature infants, but no causal links with the diseases of prematurity have been demonstrated (8). We have previously reported that protein carbonyl levels in TA correlated positively with the concentration of the neutrophil enzyme myeloperoxidase (MPO), suggesting that activated neutrophils could be the source of the protein oxidation (4). No corresponding increase in plasma protein carbonyls was seen (9).

There is now considerable evidence to suggest that early inflammation plays an important role in the development of chronic lung disease (10-14). Neutrophils are attracted to the lungs, and ongoing neutrophil infiltration is associated with poor respiratory outcome $(13,15-17)$. Neutrophils, when stimulated, release oxidants, proteases, and other potentially inju- 
rious constituents. They generate superoxide radicals and hydrogen peroxide and release MPO, which catalyzes oxidation of chloride by hydrogen peroxide to give hypochlorous acid. Hypochlorous acid is a strong oxidant that is capable of undergoing a number of damaging reactions with cells and tissue constituents $(18-20)$. It can generate carbonyl groups on proteins, but so can a number of other oxidants (21-23). Therefore, the protein carbonyls that we measured in tracheal aspirates in association with MPO (4) are suggestive but not definitive evidence for neutrophil-mediated protein oxidation. Hypochlorous acid also reacts with tyrosyl residues in proteins to produce 3-chlorotyrosine (hereafter referred to as chlorotyrosine) and 3,5-dichlorotyrosine (24). This is a minor reaction, but as it is the only known physiologic source of chlorotyrosine, chlorotyrosine can be used as a specific marker for oxidant activity of MPO-containing cells (neutrophils and monocytes). Hydrolysis of the proteins yields free chlorotyrosine, which can be measured by gas chromatography-mass spectrometry with high sensitivity. Chlorotyrosine has been detected in proteins from stimulated neutrophils and inflammatory sites $(20,25-28)$.

Although markers of oxidative stress have been measured in the lungs of infants at risk of developing chronic lung disease, oxidative injury has not been established as a major contributor to the disease. Furthermore, in major antioxidant intervention trials with dietary selenium (29) and intratracheal superoxide dismutase (30), no improvement in respiratory outcome was achieved. As discussed in a recent review (31), antioxidant therapy may potentially inhibit some important physiologic functions of reactive oxygen species and should be contemplated with caution. To provide a firm basis for any intervention or management strategies, more evidence that reactive oxidants have a pathologic role in the disease is needed. Equally important is to identify the oxidant source. The aims of this study were to determine whether neutrophil oxidants are responsible for protein damage in the lungs of premature infants by measuring chlorinated tyrosine residues in tracheal aspirates and to relate protein damage to respiratory outcome.

\section{METHODS}

Study group. Endotracheal aspirate samples were collected at the time of clinically indicated endotracheal suctioning from infants requiring ventilation and being treated in the Christchurch Women's Hospital neonatal intensive care unit. Analyses were performed on 144 samples from 69 infants born between 1992 and 2001 with very low birth weight (birth weight $<1500 \mathrm{~g}$ ) and aged $<28 \mathrm{~d}$ at the time of sampling. The profile of this population is shown in Table 1. More than one sample was obtained from 28 infants (a total of 103 samples), and 41 infants provided one sample only. Fifty-eight samples from 36 infants born between 1992 and 1998 have been included in a previous study of MPO activity and protein carbonyl concentrations (4). Samples had been stored at $-80^{\circ} \mathrm{C}$ and were now assayed for chlorinated tyrosine residues. Eight samples were also obtained for use as control material from three term infants (birth weights $2800-3420 \mathrm{~g}$ ) who required ventilation during surgery and did not show
Table 1. Clinical details of study infants $(\mathrm{n}=69)$

$\begin{array}{ll}\text { Gestational age (wk) } & \\ \text { Mean (SD) } & 26.2(2.12) \\ \text { Range } & 23-33 \\ \text { Birth weight (g) } & \\ \quad \text { Mean (SD) } & 866(268) \\ \text { Range } & 385-1410 \\ \text { Antenatal steroids } & \\ \quad \text { Completed course } & 38 \\ \quad \text { Partial course } & 15 \\ \text { None } & 15 \\ \text { Missing data } & 1 \\ \text { Died } & 4 * \\ \text { Days ventilation [mean (range)] } & 19(1-68) \\ \text { Postnatal steroids } & 26 / 86(38 \%) \dagger \\ \text { Oxygen at 36 wk PMA } & 45 / 64(70 \%) \\ \text { Days supplemental oxygen [mean (range)] } & 77.5(5-226)\end{array}$

PMA, postmenstrual age.

* Two died $<28 \mathrm{~d}$; one died day 28-36 wk PMA; one died $>36$ wk PMA.

$\dagger$ One missing data; includes four infants enrolled in randomized controlled trial of postnatal steroids or placebo.

evidence of respiratory infection. The study was approved by the Canterbury Ethics Committee, and written informed consent was obtained from parents.

Sampling procedure. Endotracheal suctioning was performed on intubated infants when clinically indicated using a dry suctioning procedure and instillation of a small amount of saline if necessary to clear secretions as described previously (32). Suction catheters were immediately refrigerated and stored for no longer than $12 \mathrm{~h}$ before separating the supernatants from cells and cell debris and storing at $-80^{\circ} \mathrm{C}$ until analyzed.

Clinical treatment of infants. All infants were treated according to the standard protocols in the neonatal intensive care unit with no alterations in care for the purposes of this study. Blood cultures were undertaken when infants were suspected to have an infection on clinical grounds. A positive culture on the day of (three infants) or up to $7 \mathrm{~d}$ before collection of the TA sample was taken as evidence of septicemia in relation to that sample. TA were cultured only when nursing staff considered these to be purulent. Evidence of Ureaplasma urealyticum infection or colonization was not sought routinely throughout the study period and tests for this organism only became available to the clinical service in 2000 when testing was undertaken in infants considered at high risk. A high titer on MycoDuo test (Bio-Rad, Marnes La Coquette, France) performed on TA collected from 1 to $10 \mathrm{~d}$ before samples used for oxidative marker analysis was considered as positive for $U$. urealyticum.

Biochemical analyses. Protein carbonyls were measured by an ELISA involving precipitation of aspirate proteins with trichloroacetic acid, reaction with dinitrophenylhydrazine, and detection with an antibody against this reagent (23). MPO activity was determined by measuring the oxidation of tetramethylbenzidine (33) and calibrated against pure myeloperoxidase $\left(\epsilon_{430} 91000 \mathrm{M}^{-1} \mathrm{~cm}^{-1}\right)$. To establish that MPO was responsible for the peroxidase activity, the assay was carried out on nine samples in the presence and absence of dapsone, which under the conditions of the assay inhibits lactoperoxi- 
dase and eosinophil peroxidase but not MPO (34). There was only slight inhibition by dapsone $(17 \pm 13 \%)$, consistent with a majority of the activity being due to MPO. Sample dilution was corrected for by relating to total protein concentration, measured with the Bio-Rad assay (Bio-Rad Laboratories, Richmond, CA, U.S.A.). Tyrosine and 3-chlorotyrosine were analyzed using a Hewlett Packard 6890 Gas Chromatograph equipped with a $30 \mathrm{~m}$ DB17 capillary column and interfaced to a Hewlett Packard 5973 Mass Spectrometer, using an adaptation of the method of Hazen et al. (26) incorporating protein hydrolysis with methane sulfonic acid. Pulsed splitless injection was used. Aspirate protein $(40 \mu \mathrm{g})$ was desalted by gel filtration, hydrolyzed with methane sulfonic acid, and solidphase extracted. Samples were derivatized with boron trifluoride/n-propanol for $1 \mathrm{~h}$ at $100^{\circ} \mathrm{C}$, then with trifluoroacetic anhydride/ethyl acetate $(1: 4 \mathrm{vol} / \mathrm{vol})$ for $1 \mathrm{~h}$ at $65^{\circ} \mathrm{C}$. $\left[{ }^{13} \mathrm{C}_{9}\right]-$ tyrosine and 3-chlorotyrosine standards were added before hydrolysis to account for losses. ${ }^{13} \mathrm{C}$-labeled chlorinated tyrosines were prepared by equimolar addition of sodium hypochlorite to labeled tyrosine and 3-chlorotyrosine was purified by reverse-phase HPLC. Results are expressed as the number of chlorotyrosine residues per million tyrosine residues $(\mu \mathrm{mol} /$ mol). Most samples were analyzed in duplicate with a coefficient of variation of $14 \pm 14 \%(n=31)$. Concentrations of standard solutions of chlorotyrosine varied by $<10 \%$ on storage at $-80^{\circ} \mathrm{C}$ for $4 \mathrm{y}$, and chlorotyrosine:tyrosine ratios of eight aspirate samples (initially $80-720 \mu \mathrm{mol} / \mathrm{mol}$ ) reanalyzed after $1-1.5$ y of storage changed by $28 \pm 16 \mu \mathrm{mol} / \mathrm{mol}$.

Clinical outcome measures. The presence of chronic lung disease was defined as the requirement of supplementary oxygen at $36 \mathrm{wk}$ postmenstrual age. The total number of days on supplementary oxygen was also used to assess respiratory outcome.

Statistical analysis. Statistical analyses were performed using Sigma Stat (Jandel Scientific, San Rafael, CA, U.S.A.). Because the data were not normally distributed, nonparametric tests were performed. Differences between groups were assessed using the Mann-Whitney rank sum test or the KruskalWallis one-way ANOVA on ranks. Correlation coefficients (CC) between variables were analyzed using Spearman's rank order correlation.

\section{RESULTS}

Detection of chlorotyrosine, protein carbonyls, and myeloperoxidase in TA. Chlorotyrosine was detectable in all of the protein samples from VLBW infants, with a median value of $83 \mu \mathrm{mol}$ chlorotyrosine per mol tyrosine (Table 2). These levels were significantly higher $(p<0.0001)$ than for three

Table 2. Medians and interquartile ranges for chlorotyrosine, $M P O$, and protein carbonyls for all VLBW infant samples

\begin{tabular}{lccc}
\hline & Median & Interquartile range & $n$ \\
\hline Chlorotyrosine $(\mu \mathrm{mol} / \mathrm{mol}$ Tyr) & 0.083 & $0.044-0.189$ & 140 \\
MPO* (nmol/g protein) & 26 & $13-64$ & 144 \\
Protein carbonyls (nmol/mg protein) & 0.58 & $0.39-0.90$ & 143 \\
\hline
\end{tabular}

* These values represent total peroxidase activity, the majority of which was due to MPO (see Methods). term infants ventilated for reasons other than respiratory distress and with no evidence of respiratory infection. Of the seven control samples analyzed, the median chlorotyrosine level was $13 \mu \mathrm{mol} / \mathrm{mol}$ tyrosine (range $0-31$ ). MPO activities and protein carbonyl levels measured in the VLBW samples are also shown in Table 2.

As samples were collected only when clinically indicated, the ages of the infants at the time of collection varied. For determining whether chlorotyrosine levels varied with age, three groups constituting early samples $(0-3 \mathrm{~d}$ after birth; mean 2.0, SD 0.8), samples collected at $\sim 1$ wk (4-12 d; mean 6.8, SD 2.4), and later samples (13-28 d; mean 19.1, SD 4.2) were considered. As shown in Fig. 1, chlorotyrosine:tyrosine ratios increased significantly with age of the infant. As observed in our previous study (4), there were also trends toward an increase in MPO activity with age and a decrease in protein carbonyls (not shown), although with the current population these trends did not reach statistical significance.

Correlations between oxidative markers. There was a strong positive correlation between chlorotyrosine:tyrosine ratio and MPO activity, as shown in Fig. 2 for all samples from all infants (CC $0.75, p<0.0001, n=140)$. When the samples were grouped according to age at the time of sampling (with the same groups as in Fig. 1) and multiple samples from one infant were averaged, the correlation between MPO and chlorotyrosine was as strong in each group as for all of the samples. Weaker but still significant correlations were seen between MPO activity and protein carbonyls (CC 0.29, $p<0.0001$,

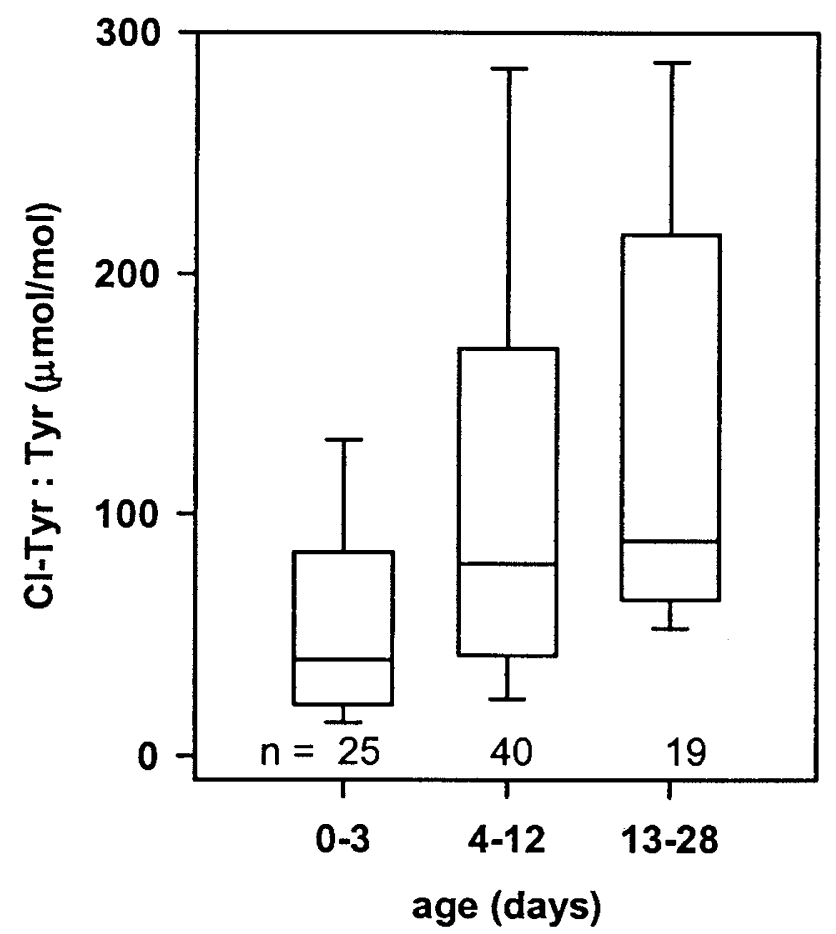

Figure 1. Chlorotyrosine:tyrosine (Cl-Tyr:Tyr) ratios in TA proteins for different age groups. Boxes show medians and interquartile ranges, with error bars representing 10th and 90th percentiles. Where multiple samples were analyzed from a single infant during the time period, the mean value was taken. Levels in the different groups are significantly different (Kruskal Wallis $p=0.005)$. 


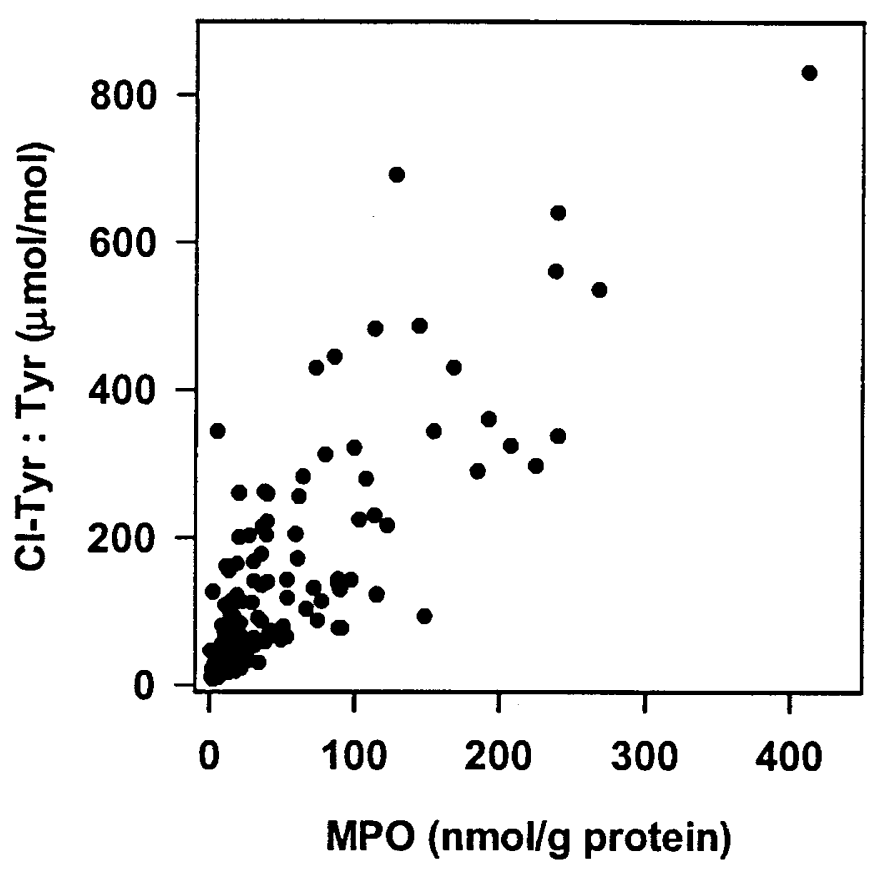

Figure 2. Correlation between MPO and chlorotyrosine:tyrosine (Cl-Tyr:Tyr) ratio for all VLBW TA samples $(n=140)$. $n=143)$ and protein carbonyls and chlorotyrosine (CC 0.26 , $p=0.002, n=139$ ). When samples were grouped according to age, correlations between protein carbonyls and MPO (CC $0.35, p=0.029, n=40$ ) or chlorotyrosine (CC 0.32, $p=$ $0.046, n=40$ ) were significant only for the $4-12 \mathrm{~d}$ group.

Effects of infection. Infection is a potential complication when considering the effects of neutrophils and neutrophil oxidants on noninfectious processes. As indices of infection, we considered a positive blood culture, confirmed lung infection, or the presence of $U$. urealyticum. Samples with any one of these positive indices had significantly higher chlorotyrosine:tyrosine ratios and MPO concentrations but not protein carbonyls than those without confirmed infection (Table 3). The increases were seen in infants with lung infection or $U$. urealyticum, and not in the group with only positive blood cultures (six of eight cases being coagulase-negative Staphylococcus). Separating the infants with identified infection also affected the strength of the biomarker correlations (Table 3 ). MPO activity remained strongly correlated with chlorotyrosine:tyrosine ratio for each group. Correlations between protein carbonyls and either MPO or chlorotyrosine were highly significant in the combined infection group but were not significant in the absence of confirmed infection. Significance was

Table 3. Effect of infection on levels of chlorotyrosine, MPO, and protein carbonyls and on the associations between the biomarkers, measured in TA samples

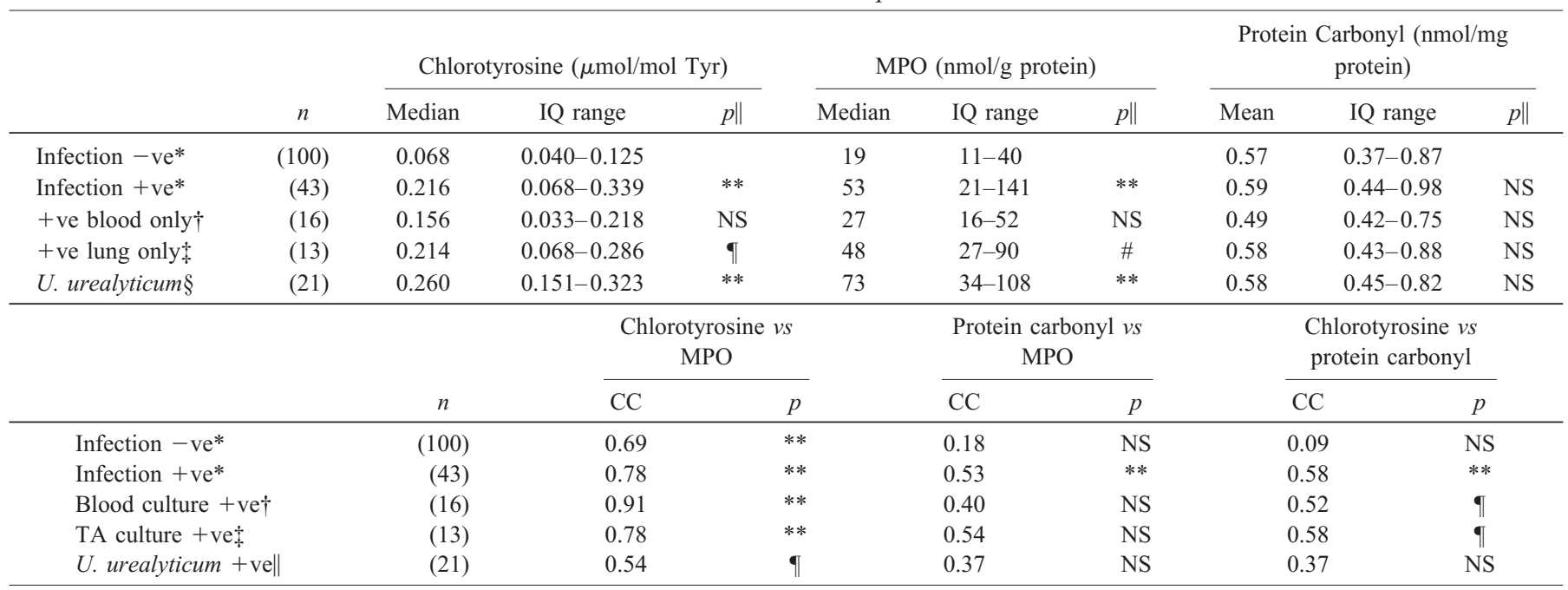

IQ, interquartile.

* Infection + ve represents combined data for samples associated with positive blood or aspirate cultures or testing positive for U. urealyticum, see text). Also included in this group is one infant (seven samples) who did not yield positive blood cultures but was born after prolonged premature rupture of the membranes for $8 \mathrm{~d}$ and had clinical and hematological evidence of sepsis and for whom a nonencapsulated Haemophilus species was cultured from both maternal vaginal and infant surface swabs. In total, there were 15 infants and 43 samples in the infection-positive group. The remaining samples were classified as infection negative.

$\dagger$ Blood culture +ve. Nine infants (16 samples) with positive blood culture on the day of or up to $7 \mathrm{~d}$ before collection of the aspirate. Seven were positive for coagulase-negative Staphylococcus, one for Staphylococcus aureus, and one for Pseudomonas cepacia. This last infant had clinical evidence of sepsis on the day of birth, and the organism was considered to be a significant pathogen.

$\ddagger$ TA culture + ve. Six infants (13 samples) with bacterial or fungal growth from TA on day of biomarker sample. One positive for Candida species alone (two samples), two positive for Eschericia coli (seven samples), one positive for both coagulase-negative Staphylococcus and Candida (two samples), one positive for coagulase-negative Staphylococcus (heavy growth), and one for Enterobacter species. Both the latter had radiological evidence of pneumonia. Four of these infants also gave positive blood cultures.

$\S U$. urealyticum + ve. Five infants (21 samples), including one of a pair of twins (the other twin testing negative on repeat sampling). All but one infant were negative for other infections. One infant (13 samples) gave positive blood and aspirate cultures. Two U. urealyticum-positive samples from this infant were not analyzed for chlorotyrosine.

$\|$ Compared with infection negative; $\mathbb{q}<0.05, \# p<0.01, * * p<0.0001$ 
lost when the infection group was subdivided into categories, probably because sample sizes became too small.

Relationships with gestational age and respiratory outcome. Chlorotyrosine:tyrosine ratios were negatively associated with gestational age (for all samples CC $-0.36, p<$ $0.0001, n=140$ ). This association was strongest for samples collected between days 4 and 12 (CC $-0.51, p<0.0001, n=$ 40 for days $4-12$; Fig. 3 ) or later and not significant for day $0-3$ samples.

Chlorotyrosine:tyrosine ratios correlated positively with the total number of days on oxygen the infant required (CC 0.33 , $p<0.0001, n=117$ for all samples). This relationship was strongest for samples taken between days 4 and 12 of life (CC $0.53, p=0.001, n=33$; Fig. 4). It was still significant for later samples but not apparent for those collected between days 0 and 3. Multiple linear regression indicated that the association between chlorotyrosine and days of oxygen requirement can mostly be explained by the relationship between oxygen requirement and gestational age (chlorotyrosine $p=0.067$; gestational age $p<0.0001$ for all samples).

Chlorotyrosine:tyrosine ratios for samples in the day 4-12 age group were significantly higher for infants requiring oxygen at $36 \mathrm{wk}$ postmenstrual age than for those who did not (Fig. 5). In making this analysis, one infant with clinical evidence of sepsis (but no positive blood culture) who did not develop chronic lung disease was excluded. She had extremely high chlorotyrosine levels on more than one occasion, the reasons for which are not known. There was no significant association between chlorotyrosine and chronic lung disease for samples in the other age groupings, and, as in our previous study, no significant relationships between MPO activity or protein carbonyl level and respiratory outcome measures were evident.

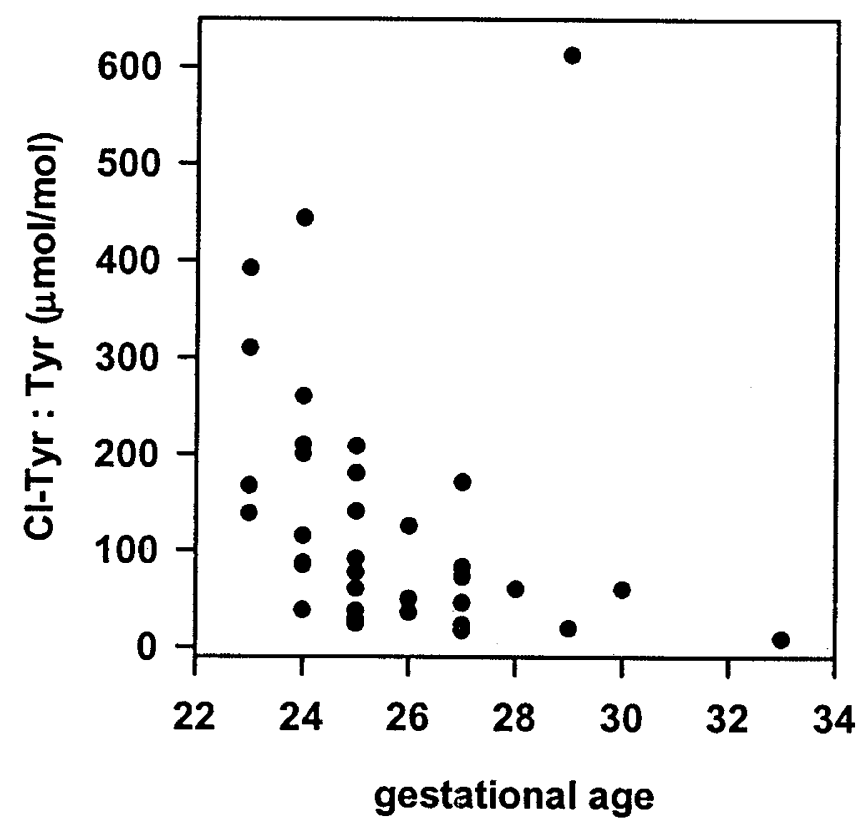

Figure 3. Relationship between aspirate chlorotyrosine:tyrosine (Cl-Tyr:Tyr) ratio and gestational age of infant at birth for samples collected between days 4 and 12 . Where multiple samples were analyzed from a single infant during the time period, the mean value was taken $(n=40)$.

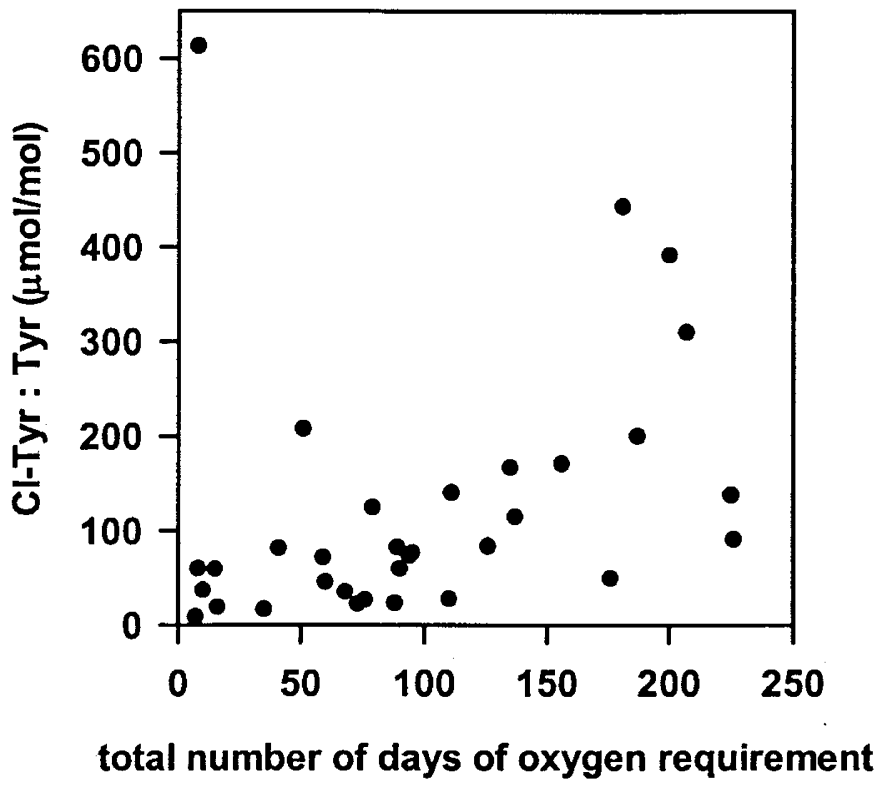

Figure 4. Relationship between aspirate chlorotyrosine:tyrosine (Cl-Tyr:Tyr) ratio in samples collected between days 4 and 12 and days of supplemental oxygen requirement, as in Fig. $3(n=33)$.

There was no correlation between the fraction of inspired oxygen $\left(\mathrm{FiO}_{2}\right)$ on the day of sample collection and chlorotyrosine level, protein carbonyl level, or MPO activity. Too few infants (4) had received postnatal steroids for at least $2 \mathrm{~d}$ before aspirate collection to assess their effects on biomarker levels. Correction for gestational age, birth weight, whether antenatal steroids had been given, Apgar scores at 1 and 5 min, or $\mathrm{FiO}_{2}$ values at the time of sampling had no effect on the associations between biomarkers in multiple linear regression analyses.

\section{DISCUSSION}

Our results provide the first evidence that proteins are chlorinated in the lung lining fluid of premature infants with respiratory distress, and the extent of chlorination varies with the clinical condition of the infants. Chlorotyrosine was detectable in all of the aspirates from premature infants, and levels were on average 4-fold higher than seen in control infants who were ventilated for reasons other than respiratory distress. The only known physiologic route to chlorotyrosine is through a reaction of MPO-derived hypochlorous acid. The observed correlation between chlorotyrosine levels and MPO activity substantiates this mechanism. Our results, therefore, are evidence that neutrophils in the infants' lungs release reactive oxidants, including hypochlorous acid, which chlorinates protein tyrosyl residues. Chlorination of tyrosine is only a minor reaction of hypochlorous acid but provides a biomarker for other reactions that can damage tissue constituents (20).

We have previously observed elevated levels of protein carbonyls in the lungs of infants with respiratory distress (4). A number of oxidants can give rise to protein carbonyls, but the association observed with MPO activity in the aspirates led us to propose that neutrophil oxidants were involved in carbonyl formation. Our current findings of positive correlations between carbonyls and both MPO and chlorotyrosine support this 


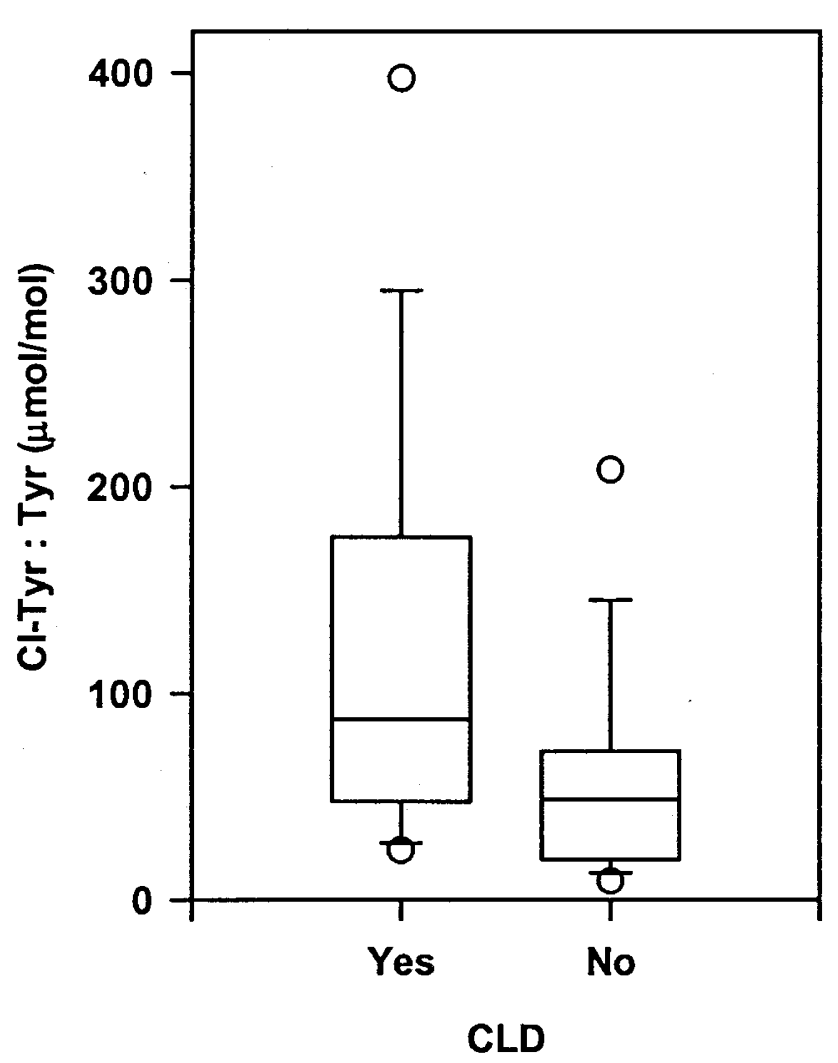

Figure 5. Chlorotyrosine:tyrosine (Cl-Tyr:Tyr) ratios in aspirate samples collected between days 4 and 12 from infants that did $(n=28)$ and did not $(n$ $=10$ ) develop chronic lung disease. Where multiple samples from a single infant were analyzed, mean values were taken. One infant died before $36 \mathrm{wk}$ postmenstrual age. The one infant with clinical signs of infection and extremely high chlorotyrosine levels (mean $61 \mu \mathrm{mol} / \mathrm{mol}$ tyrosine) who did not develop chronic lung disease is not included. Box plots show medians and interquartile ranges, 10th and 90th percentiles, and symbols at the 5th and 95th percentiles.

proposal. These correlations were weaker than between chlorotyrosine and MPO, and their strength came mainly from infants with confirmed infection. This suggests that neutrophil oxidants are not the only source of protein carbonyls in infants with respiratory distress. Their greater contribution in infection is presumably because of an associated neutrophil response. The lack of correlation with $\mathrm{FiO}_{2}$ suggests that inspired oxygen alone is not a major determinant of protein carbonyl formation.

As shown previously (4), protein carbonyl levels tend to decline with days after birth and to become more strongly associated with MPO activity. In contrast, the results of the current study show that chlorotyrosine levels increase after the first few days. This is consistent with the known pattern of neutrophil infiltration, contingent on an early inflammatory state set up in the lungs of these infants $(12,13,16)$. The neutrophil accumulation and activation to generate reactive oxidants is manifest as the chlorination of proteins to form chlorotyrosine.

Infants who went on to develop chronic lung disease had significantly higher aspirate chlorotyrosine levels than those who did not. This association was strongest for levels measured at $\sim 1$ wk after birth (4-12 d) and was also evident as a positive association between chlorotyrosine level and the days the infant remained on supplemental oxygen. This was not an independent relationship, as there was also a strong negative correlation between chlorotyrosine level at this time and gestational age at birth. Thus, the most premature infants, who are at the greatest risk of developing chronic lung disease, had the highest chlorotyrosine levels. This implicates neutrophil oxidants and their reactions, e.g. with proteins to give chlorotyrosine, as one of the contributors to the poorer respiratory outcome in these infants.

Others have noted an association between high neutrophil counts in the lungs and increased likelihood of developing chronic lung disease $(12,13,16)$. Thus, it could be argued that chlorotyrosine measurements merely reflect neutrophil accumulation and may not indicate a specific role for oxidants as against release of other potentially injurious neutrophil constituents. However, if they were simply a reflection of neutrophil accumulation, then MPO activity should be as good an indicator. Although MPO activity correlated with chlorotyrosine in the TA, only chlorotyrosine levels showed a significant relationship to respiratory outcome. Antioxidant defenses may be less well developed in the more premature infants $(31,35-37)$, in which case an equivalent level of reactive oxidant production would be expected to be more damaging to those infants. Therefore, our results could reflect a combination of oxidant production and antioxidant defense and could indicate a contributory role for neutrophil oxidants in chronic lung disease.

Our numbers were too small to assess any effects of postnatal steroids. Meta-analysis of postnatal steroid treatment of ventilated preterm infants shows that their use is associated with successful extubation and decreased rates of chronic lung disease, although there are also concerns about adverse neurodevelopmental outcome (38). It is probable that any future trials of postnatal steroids will use short courses at lower doses than formerly. As one proposed mechanism of action is to dampen down an inflammatory response, it would be desirable to measure chlorotyrosine levels as a biomarker of neutrophil oxidant activity.

There is increasing interest in the roles of inflammation and infection in the development of chronic lung disease $(11,12$, $14,39-41)$. We saw higher MPO and chlorotyrosine levels in aspirates from infants with confirmed lung infection or who tested positive for $U$. urealyticum but not in those with systemic infection. In theory, neutrophils would be expected to mount a localized oxidative response to an infectious agent. The role of infection in chronic lung disease is complex. It could be a confounding factor for identifying relationships between oxidative biomarkers and chronic lung disease. Alternatively, it could contribute to the development of the disease. The elevations of MPO and chlorotyrosine in association with $U$. urealyticum are particularly striking. Further prospective investigations, with larger numbers and focusing more specifically than in the present study on the presence of infection and inflammatory markers, are needed to further clarify these relationships.

Chlorotyrosine has been measured in relatively few clinical studies since it was first proposed as a marker for neutrophil oxidant activity (42). Elevated levels have been reported for atherosclerotic lesions (43) and in various lung diseases 
(44-47). In comparison with other studies, our chlorotyrosine:tyrosine ratios are in the same range as observed in lung allografts (46) and in individuals with severe asthma (45). Values have been reported for sputum in cystic fibrosis (47) and bronchoalveolar lavage (BAL) proteins in adult respiratory distress syndrome (ARDS) (44) that were 10-fold higher than for their controls. However, the control levels in these studies were at least 10 times or 50 times, respectively, higher than in our study, and the likelihood of artifactual chlorination during processing (48) must be considered. It has recently been reported that free chlorotyrosine is elevated in the peritoneal fluid of mice with life-threatening sepsis (28). Along with a case study of meningitis (49), our study provides evidence of elevated protein chlorination associated with infection in humans.

\section{CONCLUSIONS}

In conclusion, we have detected chlorotyrosine in TA proteins and demonstrated that it is present in significantly higher amounts in preterm infants with respiratory distress than in control infants. Infants who subsequently developed chronic lung disease were also found to have higher chlorotyrosine levels at $\sim 1$ wk of age than those who did not. Further use of this selective biomarker assay should be a valuable tool for establishing whether neutrophil oxidants indeed have a causal role in chronic lung disease as well as for monitoring effectiveness of intervention strategies.

Acknowledgments. We thank Dr. Fook-Choe Cheah and Tessa Mocatta for assistance with sample handling and documentation, Melanie Coker for differential peroxidase assays, and the nursing staff in the neonatal intensive care unit of Christchurch Women's Hospital for tirelessly taking samples and organizing delivery to the laboratory.

\section{REFERENCES}

1. Pitkänen OM, Hallman M, Andersson SM 1990 Correlation of free oxygen radicalinduced lipid peroxidation with outcome in very low birth weight infants. J Pediatr 116:760-764

2. Varsila E, Pitkänen OM, Hallman M, Andersson S 1994 Immaturity-dependent free radical activity in premature infants. Pediatr Res 36:55-59

3. Wispe JR, Bell EF, Roberts RJ 1985 Assessment of lipid peroxidation in newborn infants and rabbits by measurements of expired ethane and pentane: influence of parenteral lipid infusion. Pediatr Res 19:374-379

4. Buss IH, Darlow BA, Winterbourn CC 2000 Elevated protein carbonyls, lipid peroxidation products and myeloperoxidase in tracheal aspirates from premature infants. Pediatr Res 47:640-645

5. Gladstone IM, Levine RL 1994 Oxidation of proteins in neonatal lungs. Pediatrics 93:764-768

6. Schock BC, Sweet DG, Halliday HL, Young IS, Ennis M 2001 Oxidative stress in lavage fluid of preterm infants at risk of chronic lung disease. Am J Physiol 281:L1386-L1391

7. Varsila E, Pesonen E, Andersson A 1995 Early protein oxidation in the neonatal lung is related to development of chronic lung disease. Acta Paediatr 84:1296-1299

8. Saugstad OD 2001 Chronic lung disease: oxygen dogma revisited. Acta Paediatr $90: 113-115$

9. Winterbourn CC, Chan TP, Buss IH, Inder TE, Mogridge N, Darlow BA 2000 Protein carbonyls and lipid peroxidation products as oxidation markers in preterm infan plasma: associations with chronic lung disease and retinopathy and effect of selenium supplementation. Pediatr Res 48:84-90

10. Zimmerman JJ 1995 Bronchoalveolar inflammatory pathophysiology of bronchopulmonary dysplasia. Clin Perinatol 22:429-457

11. Watterberg KL, Demers LM, Scott SM, Murphy S 1996 Chorioamnionitis and early lung inflammation in infants in whom bronchopulmonary dysplasia develops. Pediatrics 97:210-215

12. Speer CP 1999 Inflammatory mechanisms in neonatal chronic lung disease. Eur J Pediatr 158(suppl 1):S18-S22
13. Groneck P, Gotze-Speer B, Opperman M, Eiffert H, Speer CP 1994 Association of pulmonary inflammation and increased microvascular permeability during the development of bronchopulmonary dysplasia: a sequential analysis of inflammatory mediators in respiratory fluids of high risk preterm neonates. Pediatrics 93:712-718

14. De Dooy JJ, Mahieu LM, Van Bever HP 2001 The role of inflammation in the development of chronic lung disease in neonates. Eur J Pediatr 160:457-463

15. Merritt TA, Stuard ID, Puccia J, Wood B, Edwards DK, Finkelstein J, Shirpiro DL 1981 Newborn tracheal aspirate cytology: classification during respiratory distress syndrome and bronchopulmonary dysplasia. J Pediatr 98:949-956

16. Jackson TC, Chi EY, Wilson CB 1987 Sequence of inflammatory cell migration into lung during recovery from hyaline membrane disease in premature newborn monkeys. Am Rev Respir Dis 135:937-940

17. Ogden BE, Murphy SA, Saunders GC, Pathak D, Johnson JD 1984 Neonatal lung neutrophils and elastase/proteinase inhibitor imbalance. Am Rev Respir Dis 130:817-821

18. Kettle AJ, Winterbourn CC 1997 Myeloperoxidase: a key regulator of neutrophil oxidant production. Redox Rep 3:3-15

19. Pullar JM, Vissers MCM, Winterbourn CC 2000 Living with a killer: the effects of hypochlorous acid on mammalian cells. IUBMB Life 50:259-266

20. Winterbourn CC, Kettle AJ 2000 Biomarkers of myeloperoxidase-derived hypochlorous acid. Free Radic Biol Med 29:403-409

21. Stadtman ER 1990 Metal ion catalysed oxidation of proteins: biochemical mechanism and biological consequences. Free Radic Biol Med 9:315-325

22. Chapman ALP, Senthilmohan R, Winterbourn CC, Kettle AJ 2000 Comparison of mono and dichlorinated tyrosines with carbonyls for detection of hypochlorous acid-modified proteins. Arch Biochem Biophys 377:95-100

23. Winterbourn CC, Buss IH 1999 Protein carbonyl measurement by enzyme-linked immunosorbent assay. Methods Enzymol 300:106-111

24. Kettle AJ 1996 Neutrophils convert tyrosyl residues in albumin to chlorotyrosine. FEBS Lett 379:103-106

25. Hazen SL, Heinecke JW 1997 3-Chlorotyrosine, a specific marker of myeloperoxidase-catalyzed oxidation, is markedly elevated in low density lipoprotein isolated from human atherosclerotic intima. J Clin Invest 99:2075-2081

26. Hazen SL, Crowley JR, Mueller DM, Heinecke JW 1997 Mass spectrometric quantification of 3-chlorotyrosine in human tissues with attomole sensitivity: a sensitive and specific marker for myeloperoxidase-catalyzed chlorination at sites of inflammation. Free Radic Biol Med 23:909-916

27. Chapman ALP, Hampton MB, Senthilmohan R, Winterbourn CC, Kettle AJ 2002 Chlorination of bacterial and neutrophil proteins during phagocytosis and killing of Staphylococcus aureus. J Biol Chem 277:9757-9762

28. Gaut JP, Yeh GC, Tran HD, Byun J, Henderson JP, Richter GM, Brennan ML, Lusis AJ, Belaaouaj A, Hotchkiss RS, Heinecke JW 20011966 Neutrophils employ the myeloperoxidase system to generate antimicrobial brominating and chlorinating oxidants during sepsis. Proc Natl Acad Sci U S A 98:11961-11966

29. Darlow BA, Winterbourn CC, Inder TE, Graham PJ, Harding JE, Weston PJ, Austin NC, Elder DE, Mogridge N, Buss IH, Sluis KB 2000 The effect of selenium supplementation on outcome in very low birthweight infants: a randomised controlled trial. J Pediatr 136:473-480

30. Suresh GK, Davis JM, Soll RF 2001 Superoxide dismutase for preventing chronic lung disease in mechanically ventilated preterm infants. Cochrane Database Syst Rev 1:CD001968

31. Jankov RP, Negus A, Tanswell AK 2001 Antioxidants as therapy in the newborn: some words of caution. Pediatr Res 50:681-687

32. Darlow BA, Sluis KB, Inder TE, Winterbourn CC 1997 Endotracheal suctioning of the neonate: balancing clinical and research needs. Pediatr Pulmonol 23:217221

33. Bozeman PM, Learn DB, Thomas EL 1990 Assay of the human leukocyte enzymes myeloperoxidase and eosinophil peroxidase. J Immunol Methods 126:125-133

34. Thomas EL, Jefferson MM, Joyner RE, Cook GS, King CC 1994 Leukocyte myeloperoxidase and salivary lactoperoxidase: identification and quantitation in human mixed saliva. J Dent Res 73:544-555

35. Frank L, Sosenko IRS 1987 Development of lung antioxidant enzyme system in late gestation: possible implications for the prematurely born infant. J Pediatr 110:9-14

36. Welty SE, Smith CV 2001 Rationale for antioxidant therapy in premature infants to prevent bronchopulmonary dysplasia. Nutr Rev 59:10-17

37. Kelly FJ 1993 Free radical disorders of preterm infants. Br Med Bull 49:668-678

38. American Academy of Pediatrics and Canadian Paediatric Society 2002 Postnatal corticosteroids to treat or prevent chronic lung disease in preterm infants. Pediatrics 109:330-338

39. Vigneswaran R 2000 Infection and preterm birth: evidence of a common causal relationship with bronchopulmonary dysplasia and cerebral palsy. J Paediatr Child Health 36:293-296

40. Abele-Horn M, Genzel-Boroviczeny O, Uhlig T, Zimmermann A, Peters J, Scholz M 1998 Ureaplasma urealyticum colonization and bronchopulmonary dysplasia: a comparative prospective multicentre study. Eur J Pediatr 157:1004-1011

41. Van Marter LJ, Dammann O, Allred EN, Leviton A, Pagano M, Moore M, Martin C 2002 Chorioamnionitis, mechanical ventilation, and postnatal sepsis as modulators of chronic lung disease in preterm infants. J Pediatr 140:171-176

42. Domigan NM, Charlton TS, Duncan MW, Winterbourn CC, Kettle AJ 1995 Chlorination of tyrosyl residues in peptides by myeloperoxidase and human neutrophils J Biol Chem 270:16542-16548

43. Podrez EA, Abu-Soud HM, Hazen SL 2000 Myeloperoxidase-generated oxidants and atherosclerosis. Free Radic Biol Med 28:1717-1725

44. Lamb NJ, Gutteridge JM, Baker C, Evans TW, Quinlan GJ 1999 Oxidative damage to proteins of bronchoalveolar lavage fluid in patients with acute respiratory distress 
syndrome: evidence for neutrophil-mediated hydroxylation, nitration, and chlorination. Crit Care Med 27:1738-1744

45. MacPherson JC, Comhair SA, Erzurum SC, Klein DF, Lipscomb MF, Kavuru MS Samoszuk MK, Hazen SL 2001 Eosinophils are a major source of nitric oxide-derived oxidants in severe asthma: characterization of pathways available to eosinophils for generating reactive nitrogen species. J Immunol 166:5763-5772

46. De Andrade JA, Crow JP, Viera L, Bruce AC, Randall YK, McGiffin DC, Zorn GL, Zhu S, Matalon S, Jackson RM 2000 Protein nitration, metabolites of reactive nitrogen species, and inflammation in lung allografts. Am J Respir Crit Care Med 161:2035-2042
47. van der Vliet A, Nguyen MN, Shigenaga MK, Eiserich JP, Marelich GP, Cross CE 2000 Myeloperoxidase and protein oxidation in cystic fibrosis. Am J Physio 279:L537-L546

48. Gaut JP, Byun J, Tran HD, Heinecke JW 2002 Artifact-free quantification of free 3-chlorotyrosine, 3-bromotyrosine, and 3-nitrotyrosine in human plasma by electron capture-negative chemical ionization gas chromatography mass spectrometry and liquid chromatographyelectrospray ionization tandem mass spectrometry. Anal Biochem 300:252-259

49. Inder TE, Mocatta T, Darlow BA, Spencer C, Senthilmohan R, Winterbourn CC, Volpe JJ 2002 Elevation of oxidative injury markers in the CNS with periventricular leukomalacia in a premature infant with meningitis. J Pediatr 140:617-621 